edge of the screen and is just sufficient to enable one to see the lens case and write notes. The screen can readily be swung to one side for oblique illumination of the eye, or to illuminate the test type; though personally I prefer to keep the patient sitting where the retinoscopy is done, and I have another Adjusto-lite clipped at the opposite side of the room beside the test card.

The Adjusto-lite has eight feet of flex and its base incorporates a strong felt-lined clip so that it can readily be fastened in any position and to most articles of furniture. The cost of the Adjustolite and Thomas Screen is two guineas and the whole outfit can be carried in the Adjusto-lite box in an attaché case.

\title{
ANNOTATIONS
}

\section{Rebuilding of the Royal Westminster Ophthalmic Hospital}

An important addition to the facilities for the study and practice of ophthalmology in London will be provided by the removal of the Royal Westminster Ophthalmic Hospital to a new and larger building in Broad Street, W.C.2, near the junction of Tottenham Court Road and New Oxford Street.

This hospital was founded in the year 1816 by Mr. G. J. Guthrie (v. Brit. Jl. of Ophthal., Vol. III, p. 145, 1919) under the patronage of the Duke of York and with the active support of the first Duke of Wellington, under whom Guthrie had served with great distinction as an Army Surgeon during the Peninsular War. An immense amount of disablement had been caused among the troops serving in the Napoleonic Wars by disorders of the eyes, especially by the so-called Egyptian ophthalmia. One of Guthrie's chief objects in founding the hospital was to enable medical officers of the Army and Navy to obtain instruction in the treatment of diseases of the eye, and he admitted such officers without fee to his courses of lectures.

Guthrie first saw patients at his private house in Berkeley Street, on the site of the present Berkeley Hotel. On January 1, 1817, the hospital was first opened in Marylebone Street, Piccadilly; later it was moved to Warwick Street, Golden Square. The building in King William Street, West Strand, was opened in 1832 and there the hospital remained for ninety-six years. Enlargements and alterations were made from time to time to provide increased accommodation, but the limits of extension upon the old site were reached some years ago, and removal to a larger site became 
imperative if the work of the hospital was to be efficiently carried on.

The out-patient department in the new building was opened on April 10 last, and it is hoped that the remainder of the hospital will be completed within a few weeks. An important feature of the new hospital is the provision of a number of rooms for paying patients, in order to meet the needs of those who cannot afford the cost of treatment in private nursing homes.

\section{The Oculist}

In the Trans. Ophthal. Soc. U.K., 1921, p. 342, will be found an account of Sir William Read, Oculist to Queen Anne. A tract in the British Museum, with the above title was alluded to as a fulsome eulogy. We recently secured a copy of the tract in question and give some extracts here for the amusement of our readers.

The tract is a small quarto, published in 1705 ; it is anonymous, and consists of five pages of introduction and 113 lines of poetry. Sufficient extracts from the introduction are given in the paper in question; here we propose to take a few couplets from the poem.

"The OCUILIST moves in an Orb more bright :-

The EYE's his Province; that bright Optick Sphere, By which we move, and act, and guide, and steer.-

No Price too high the darling EYES to save,

When .Life without 'em's but a walking Grave.--

And if bold Esculapius cou'd aspire

So high, to claim Apollo for his Sire,

The OCULIST, with his more shining WORTH, Is sure the radiant Phoebus Eldest Birth :-

READ is the leading CONQUEROR in this Field.-

Your ministring Art and unbought Labours given

For no Return, unless repay'd by Heav'n.

So frankly good, and so profusely kind,

Has Your long Charitable Glory shin'd;

So bred in tender Pity's generous School,

Kind as the Angel at Bethesda's Pool."-

Enough extracts have been given from this poem; it would have been interesting to have known who was the author of these lines. They should be compared with the lines by the Chevalier Taylor's grandson, quoted by Coats in the last volume of the Moorfields Hospital Reports. To the best of our recollection they deal with 